\title{
Essential opaque bubble layer elimination with novel LASIK flap settings in the FS200 Femtosecond Laser
}

This article was published in the following Dove Press journal:

Clinical Ophthalmology

I8 April 2013

Number of times this article has been viewed

\section{A John Kanellopoulos ${ }^{1,2}$ George Asimellis'}

'Laservision.gr Eye Institute, Athens, Greece; ${ }^{2} \mathrm{New}$ York University School of Medicine, New York, NY, USA

Video abstract

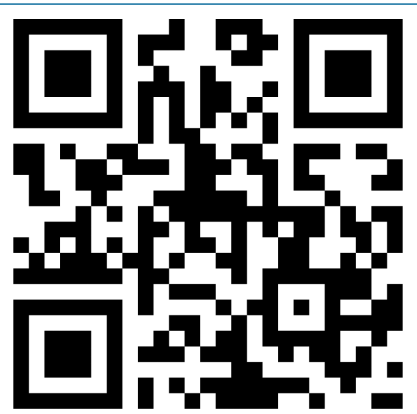

Point your SmartPhone at the code above. If you have a QR code reader the video abstract will appear. Or use: http://dvpr.es/2Nk4F5

Correspondence: A John Kanellopoulos Laservision.gr Eye Institute

I7A Tsocha Str, Athens, Greece II52 I

Tel +30210 7472777

Fax+30210747 2789

Email ajk@brilliantvision.com
Background: The purpose of this study is to evaluate the extent and incidence of opaque bubble layer (OBL) using laser-assisted in situ keratomileusis (LASIK) flaps created with the Alcon/WaveLight ${ }^{\circledR}$ FS200 femtosecond laser as a result of a recent change in flap programming parameters aiming to reduce further the incidence and extent of OBL.

Methods: Intraoperative digital images of flaps from 36 consecutive patients ( 72 eyes) subjected to bilateral femtosecond-assisted LASIK were analyzed using a proprietary computerized technique. The incidence and extent of OBL was measured and reported as a percentage of the entire flap area. Flap creation was performed with a $1.7 \mathrm{~mm}$ wide canal, implemented as an updated design intended to reduce the extent of OBL (group A). The same OBL parameters were investigated and compared in an age-matched and procedure-matched patients in whom the previous standard setting of a $1.3 \mathrm{~mm}$ wide canal was implemented (group B).

Results: In group A, the average extent of OBL was $3.69 \%$ of the flap area (range $0 \%-11.34 \%$ ). In group B, the respective values were $6.06 \%$ (range $0 \%-20.24 \%$ ). We found the difference to be statistically significant (one-tailed $P=0.00452$ ).

Conclusion: This study suggests that there is a significant reduction in the incidence and extent of OBL when novel LASIK flap ventilation canal parameters of width and spot line separation are used.

Keywords: femtosecond laser flap, bladeless laser-assisted in situ keratomileusis, opaque bubble layer, Alcon/WaveLight FS200, spot line separation

\section{Introduction}

Formation of opaque bubble layer (OBL) during creation of a laser-assisted in situ keratomileusis (LASIK) flap is a finding unique to use of femtosecond laser. ${ }^{1}$ OBL occurs along the lamellar dissection plane during the flap creation, ${ }^{2}$ and can be described simply as temporary stromal infiltration by compressed air generated by the intracorneal femtosecond laser action, that cannot escape. ${ }^{3}$

Although no serious complications have been reported as a result of its occurrence, OBL may temporarily obscure the pupil image used by most excimer laser trackers, in the subsequent excimer ablation. It may also interfere with reading of architectural landmarks on the iris used by some excimer laser trackers to compensate for cyclorotation, and may even obscure the patient's fixation target.

The purpose of this study was to compare quantitative differences in the presence and extent of OBL in flaps created using the FS200 femtosecond laser with a recently introduced wider venting canal design, and tighter line separation parameters, versus the predecessor design. 


\section{Materials and methods}

This study was approved by the ethics committee of our institution, and was consistent with the tenets of the Declaration of Helsinki. Informed consent was obtained from each subject at the time of the LASIK intervention or the first clinical screening visit. The study was conducted in our clinical LASIK practice and recruited consecutive patients.

\section{Patient inclusion criteria}

The study group consisted of 36 consecutive patients (72 eyes) treated with bilateral primary myopic or hyperopic femtosecond-assisted LASIK between October 2012 and January 2013 at our center, forming the "wide canal" group (group A). Specifically, the canal width was $1.7 \mathrm{~mm}$, with a canal spot separation of $4.0 \mu \mathrm{m}$ and a canal line separation of $2.5 \mu \mathrm{m}$ (details of the venting channel are shown in Figure 1). This wider canal with a denser line separation was introduced in order to create a potentially more efficient venting corridor. Of the 72 flaps in this group, the majority $(n=48)$ were programmed to a diameter of $8.00 \mathrm{~mm}$, while 22 flaps were programmed to $8.50 \mathrm{~mm}$ and two flaps were programmed to $9.50 \mathrm{~mm}$. This difference reflected our preference for flap parameters in standard myopic, ${ }^{4}$ wider optical zone myopic, and hyperopic LASIK, ${ }^{5}$ respectively.

A second group comprising 36 patients (72 eyes) previously treated between March 2012 and October 2012 with bilateral primary myopic or hyperopic femtosecond-assisted LASIK at our center using the "narrow canal" design, was selected to match group A in regard to flap diameter distribution (group B). In addition to the $1.3 \mathrm{~mm}$ wide canal, the canal line separation in group B patients was sparser at $4.0 \mu \mathrm{m}$.

In all procedures, which were performed by the same surgeon (AJK), the LASIK flap was created using the
WaveLight ${ }^{\circledR}$ FS200 femtosecond laser (Alcon Surgical, Fort Worth, TX, USA), and subsequent excimer ablation was performed using the WaveLight EX500 excimer laser. ${ }^{6}$

The femtosecond laser flap settings common to both groups were: stromal bed cut spot separation, $8 \mu \mathrm{m}$; line separation, $8 \mu \mathrm{m}$; side cut bed separation, $5 \mu \mathrm{m}$; line separation, $3 \mu \mathrm{m}$; side cut angle, $70^{\circ}$; bed cut pulse energy, $0.80 \mu \mathrm{J}$; side cut pulse energy, $0.80 \mu \mathrm{J}$; canal spot separation, $4.0 \mu \mathrm{m}$; and hinge angle, $45^{\circ}$.

\section{Imaging and measurement}

Intraoperative images were collected from the applanated corneas using the Alcon/WaveLight Refractive Suite WaveNet documentation software. These images are created by default during the refractive procedure and stored in the system software, and are available for documentation. Digital analysis of these images was used to determine if OBL was present, as described in detail elsewhere. ${ }^{10}$

Linear regression analysis was performed to seek possible correlations between intended versus achieved flap dimensions. Descriptive statistics (average, minimum, maximum, standard deviation, and range), comparative statistics, and linear regression were performed using Microsoft Excel 2010 (Microsoft Corporation, Redmond, WA, USA) and OriginLab version 9.0 Build B45 (OriginLab Corporation, Northampton, MA, USA). Analysis of variance between the two groups was performed using the OriginLab statistics tool.

\section{Results}

The mean subject age in group A at the time of surgery was $28.7 \pm 6.6(18-41)$ years, and the normality test $P$ value was 0.078 . The mean subject age in group B was $29.6 \pm 7.8$ (17-44) years, and the normality test $P$ value was 0.054 .
A

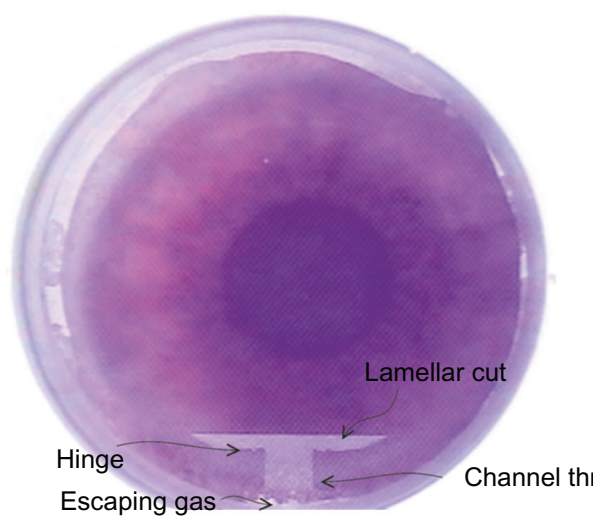

B

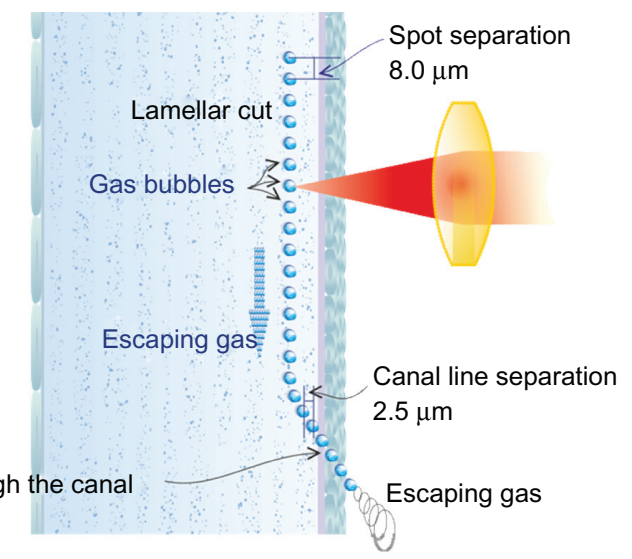

Figure I Illustration of the gas venting chimney mechanism for the FS200 femtosecond laser. (A) Top view, intraoperative surgeon's view. The canal and hinge are at the 12 o'clock position. (B) Artist's rendering of the channel through the canal created during the procedure. 
Table I Incidence of opaque bubble layer, expressed as a percentage of total flap area, with comparative results for the wide and narrow canal groups

\begin{tabular}{lll}
\hline & Wide canal group & Narrow canal group \\
\hline Eyes $(\mathrm{n})$ & 72 & 72 \\
Mean OBL area & $3.69 \%$ & $6.06 \%$ \\
Standard deviation & $3.78 \%$ & $6.58 \%$ \\
Minimum & $0.00 \%$ & $0.00 \%$ \\
Maximum & $11.34 \%$ & $20.34 \%$ \\
\hline
\end{tabular}

OBL in group A (wide canal) was digitally measured to have a mean area of $3.69 \% \pm 3.78 \%$, where the percentage indicates the fraction of the OBL area with respect to the total flap area. The maximum OBL percentage was $11.3 \%$, and the minimum was $0 \%$. Of the 72 flaps examined, 27 had no OBL present (that is, OBL area $0 \%$ ). The comparative OBL incidence metrics for both groups are presented in Table 1, and histogram data and box plots for the incidence of OBL in both groups are shown in Table 2 and Figure 2, respectively. The one-tailed $t$-test was performed because the results were expanding only in the positive direction, and yielded a value of $P=0.00452$ between the groups.

\section{Discussion}

Creation of a LASIK flap with a femtosecond laser is considered advantageous to microceratome $\mathrm{e}^{7,8}$ for a more
Table 2 Comparative OBL histogram data, expressed as \% fraction of total flap area for the two groups in the study

\begin{tabular}{lll}
\hline \begin{tabular}{l} 
OBL area $\begin{array}{l}\text { (\% of } \\
\text { total flap area) }\end{array}$ \\
\cline { 2 - 3 }
\end{tabular} & $\begin{array}{l}\text { number of cases } \\
\text { group A wide } \\
\text { canal group }\end{array}$ & $\begin{array}{l}\text { group B wide } \\
\text { canal group }\end{array}$ \\
\hline $0 \%-2 \%$ & 35 & 32 \\
$2 \%-4 \%$ & 2 & 5 \\
$4 \%-6 \%$ & 6 & 4 \\
$6 \%-8 \%$ & 17 & 5 \\
$8 \%-10 \%$ & 8 & 4 \\
$10 \%-12 \%$ & 4 & 5 \\
$12 \%-14 \%$ & 0 & 3 \\
$14 \%-16 \%$ & 0 & 7 \\
$16 \%-18 \%$ & 0 & 7 \\
$>18 \%$ & & 2 \\
\hline
\end{tabular}

centered, higher controlled-geometry, both in depth ${ }^{9}$ as well as diameter. ${ }^{10}$ In an earlier effort to validate the precision and accuracy of flap creation, we had introduced a quantitative digital analysis technique for accurate measurement of flap diameter and extent of OBL for flaps created using the Alcon/WaveLight FS200 femtosecond laser during LASIK and prior to lifting of the flap. ${ }^{10}$

A major finding of this study was that OBL was rare and consistently of the "delayed" form, and that there was a "signature" of accumulation near the sides of the canal and towards the limbus (Figure 3). Our hypothesis to explain why

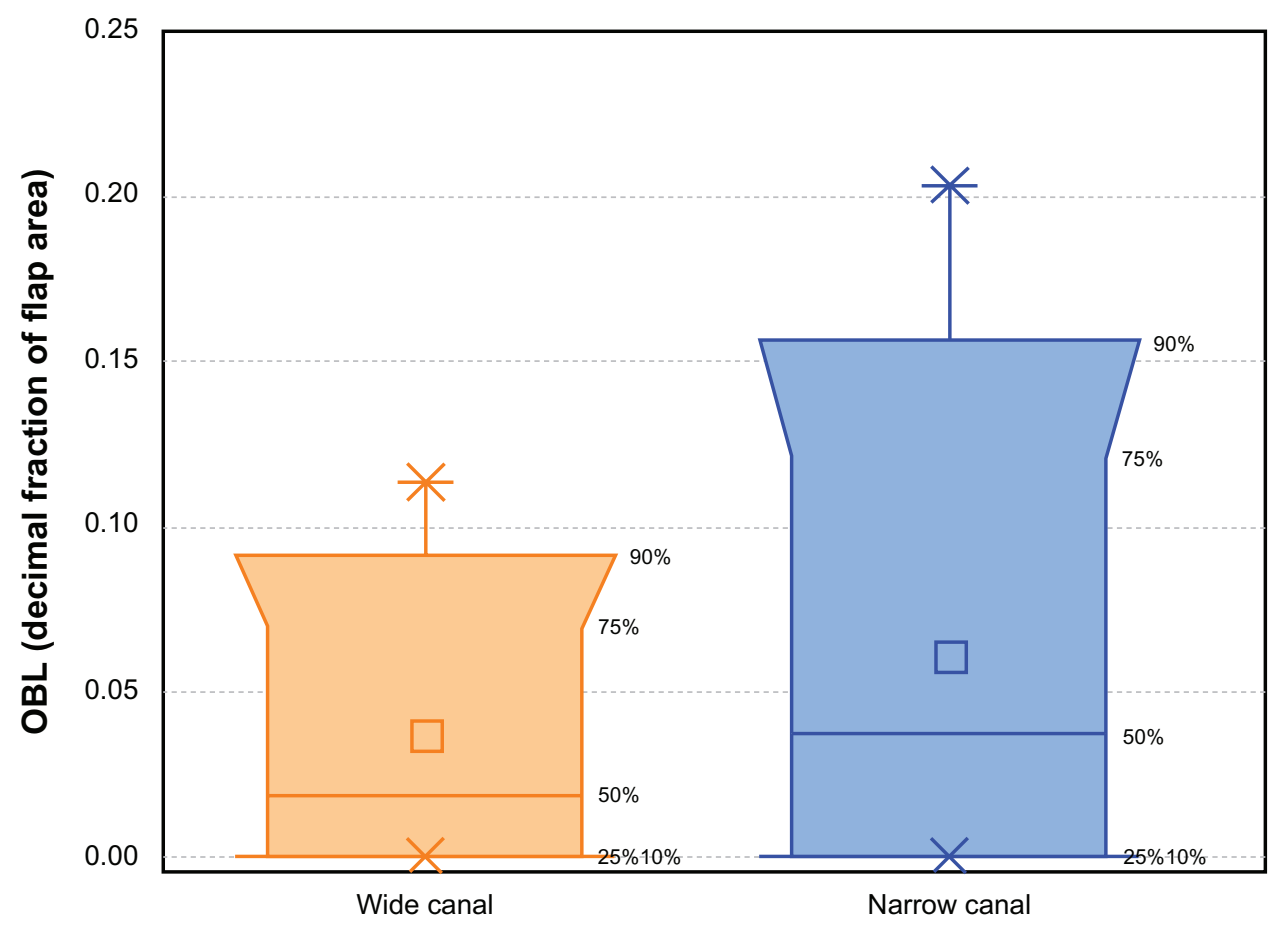

Figure 2 Box plots for OBL, expressed as fraction of the total flap area for the two groups, indicating the $99 \%$ point with the $\times$ sign, and the mean point with the $\square$ sign. Note: Vertical axis, range of extent of OBL as a fraction of total flap area.

Abbreviation: $\mathrm{OBL}$, opaque bubble layer 


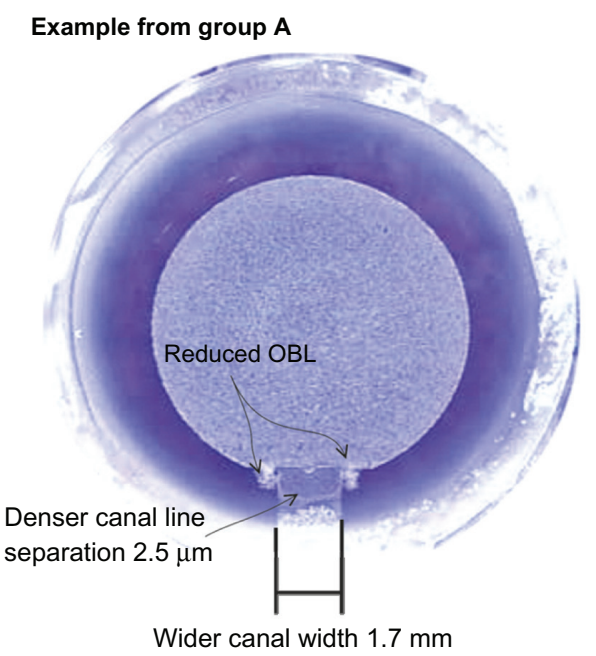

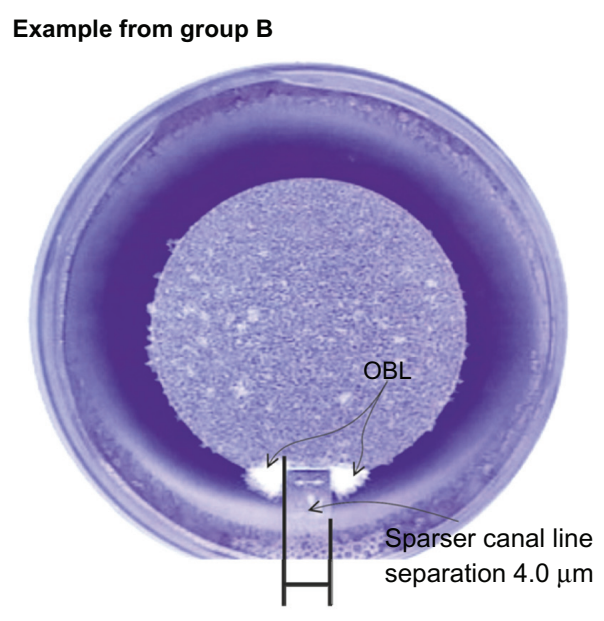

Narrower canal width $1.3 \mathrm{~mm}$

Figure 3 Two representative flaps from group A (canal width $1.7 \mathrm{~mm}$, denser canal line separation, $2.5 \mu \mathrm{m}$ ) and group B (canal width $1.3 \mathrm{~mm}$, sparser canal line separation, $4.0 \mu \mathrm{m})$.

the extent of OBL was so small is related to the proprietary technique used by the FS200 laser to address this issue, ie, flap creation starts with a venting dissection corridor which acts as a venting "chimney" along a canal designed by the surgeon. The canal, as seen by the intraoperative surgeon's view, begins from the limbal area towards the flap hinge, and in the cross-sectional view, begins from the top of the conjunctiva towards the lamellar cut bed (Figures 1 and 4). Other lasers, such as the IntraLase FS60, create a vertical gas pocket near the hinge, acting as an escape route for gas that has built up within the cornea. ${ }^{9}$ This pocket may not solve the problem, because it just presses the gas into deep looser corneal tissue, whereas the venting canals helps bring the gas out of the eye. The other disadvantages of the pocket is possible gas breakthough towards the anterior chamber, hindering subsequent eximer laser ablation.

The novel settings were implemented to test our theory that OBL can be further reduced if the chimney volume

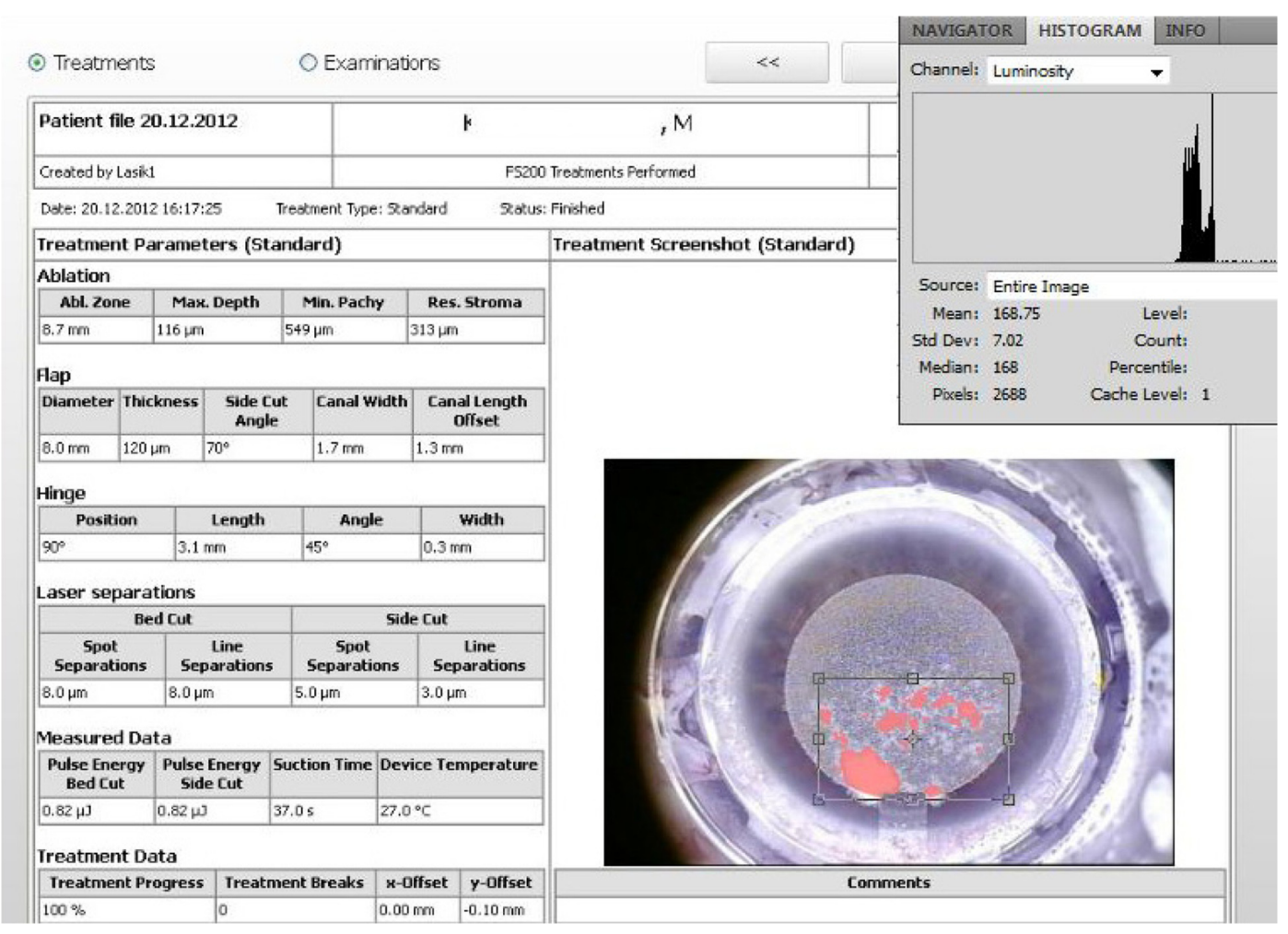

Figure 4 Digital analysis of extent of OBL.

Notes: In this example, the OBL area is 2688 pixels, while the entire flap is 29,225 pixels. The extent of the flap was measured to be $9.20 \%$ of the entire flap area. 
provided by this FS200 design is increased. Until recently, our standard canal width was $1.3 \mathrm{~mm}$. We have since introduced the $1.7 \mathrm{~mm}$ canal width, ie, the wide canal. In addition, the denser line spacing within the canal also helps to create a more efficient chimney.

Despite the significance of OBL in femtosecond-laser LASIK flap creation, there are very few reports in the peerreviewed literature regarding the extent and characteristics of OBL. ${ }^{2,11}$ Our analysis is based on immediate digital image processing of the flap creation (Figure 4), and we believe it is a novel way to document and measure the presence of OBL in a quantitative manner.

Our study shows that the incidence of OBL is small, and it appears that the novel parameters used in flap canal creation are beneficial in terms of outcome, by improving the channeling of gas buildup outside the cornea at the limbus during lamellar cornea dissection. Although not specifically evaluated in this study, the wider canal was not associated with any astigmatic induction.

The reason why OBL always appears in the hinge side of the flap is that OBL is caused by a buildup of trapped gas which is unable to vent. As the lamellar dissection of the laser progresses, the lamellar pocket space created becomes larger, thereby reducing this phenomenon. The type of OBL observed in our study was the so-called "soft" or "delayed" OBL, as opposed to "hard" or "advancing" OBL ahead of the laser breakdown raster line. Thus, even this small and further reduced appearance of delayed OBL does not interfere with laser focusing during flap creation.

With the implementation of the novel flap parameter settings, OBL was clinically nonexistent, with only with only a minute presence. Specifically, $50 \%$ of the flaps had less than $2.7 \%$ of total flap trace OBL, and only one of five of the flaps would be characterized as having actual OBL, albeit minimal, and affecting up to approximately $16 \%$ of the flap area. The reader has to consider that these incidence percentages cannot be compared with previous published studies or reports with OBL except ours. Our benchmark objective digital analysis is able to document and register clinically minute presence of OBL. It is therefore an objective and extremely stern criterion for the existence of $\mathrm{OBL}$ and its exact relative flap surface extent. Since the maximum OBL measured in the novel settings group is under $12 \%$, one can claim clinical assessment is eliminated.

Larger independent studies may be needed to validate these findings further. In the analysis reported here, our small sample yielded statistically significant data.
The two sample groups were age-matched and procedurematched, making this small study quite representative in our opinion.

\section{Conclusion}

Our study suggests that the wider canal settings along with customized denser spot application implemented in LASIK flap creation via the FS200 femtosecond laser significantly reduces the risk of $\mathrm{OBL}$.

\section{Acknowledgment}

The authors acknowledge Mr Sissimos Lemonis, clinical applications specialist for Alcon/WaveLight, who designed and supervised the onsite implementation of this novel procedure.

\section{Disclosure}

AJK does occasional consultancy work for Alcon Laboratories. GA has no conflicts of interest in this work.

\section{References}

1. Farjo AA, Sugar A, Schallhorn SC, et al. Femtosecond lasers for LASIK flap creation: a report by the American Academy of Ophthalmology. Ophthalmology. November 19, 2012. [Epub ahead of print.]

2. Kaiserman I, Maresky HS, Bahar I, Rootman DS. Incidence, possible risk factors, and potential effects of an opaque bubble layer created by a femtosecond laser. J Cataract Refract Surg. 2008;34: $417-423$.

3. Hurmeric V, Yoo SH, Fishler J, Chang VS, Wang J, Culbertson WW. In vivo structural characteristics of the femtosecond LASIK-induced opaque bubble layers with ultrahigh-resolution SD-OCT. Ophthalmic Surg Lasers Imaging. 2010;41 Suppl:S109-S113.

4. Kanellopoulos AJ, Asimellis G. Long term bladeless LASIK outcomes with the FS200 femtosecond and EX500 excimer laser workstation: the Refractive Suite. Clin Ophthalmol. 2013;7:261-269.

5. Kanellopoulos AJ. Topography-guided hyperopic and hyperopic astigmatism femtosecond laser-assisted LASIK: long-term experience with the $400 \mathrm{~Hz}$ eye-Q excimer platform. Clin Ophthalmol. 2012;6: 895-901.

6. Kanellopoulos AJ, Asimellis G. High myopia one-year refractive and keratometric stability in LASIK with high-frequency femtosecond and excimer lasers. J Refract Surg. 2013. In press.

7. Kezirian GM, Stonecipher KG. Comparison of the IntraLase femtosecond laser and mechanical keratomes for laser in situ keratomileusis. J Cataract Refract Surg. 2004;30:804-811.

8. Kanellopoulos AJ, Pe LH, Kleiman L. Moria M2 single use microkeratome head in 100 consecutive LASIK procedures. $J$ Refract Surg. 2005;21(5):476-9.

9. Kanellopoulos AJ, Asimellis G. Three-dimensional LASIK flap thickness variability: topographic central, paracentral and peripheral assessment, in flaps created by a mechanical microkeratome (M2) and two different femtosecond lasers. Clin Ophthalmol. 2013;7:675-683.

10. Kanellopoulos AJ, Asimellis G. Digital analysis in flap parameter accuracy and opaque bubble layer objective assessment in femtosecond laser assisted LASIK. A novel technique. Clin Ophthalmol. 2013;7: 343-351.

11. Soong HK, Malta JB. Femtosecond lasers in ophthalmology. Am J Ophthalmol. 2009;147:189-197. e2. 


\section{Publish your work in this journal}

Clinical Ophthalmology is an international, peer-reviewed journal covering all subspecialties within ophthalmology. Key topics include: Optometry; Visual science; Pharmacology and drug therapy in eye diseases; Basic Sciences; Primary and Secondary eye care; Patient Safety and Quality of Care Improvements. This journal is indexed on

Submit your manuscript here: http://www.dovepress.com/clinical-ophthalmology-journal
PubMed Central and CAS, and is the official journal of The Society of Clinical Ophthalmology (SCO). The manuscript management system is completely online and includes a very quick and fair peer-review system, which is all easy to use. Visit http://www.dovepress.com/ testimonials.php to read real quotes from published authors. 